\title{
Effect of Tricalcium Silicate on Direct Pulp Capping: Experimental Study in Rats
}

\author{
Lúcio P.G. Chicarelli ${ }^{1}$ Mariana B.F. Webber ${ }^{1} \quad$ João P.A. Amorim ${ }^{1} \quad$ Ana L.C.A. Rangel ${ }^{1}$ \\ Veridiana Camilotti ${ }^{1}$ Mario A.C. Sinhoreti ${ }^{2}$ Marcio J. Mendonça ${ }^{1}$
}

${ }^{1}$ Dental School, State University of Western Paraná, Cascavel, Paraná, Brazil

2Piracicaba Dental School, University of Campinas, Piracicaba, São Paulo, Brazil

\begin{abstract}
Address for correspondence Marcio J. Mendonça, DDS, MS, PhD, Department of Prosthodontics, Dental School Rua Universitária, 2069-Faculdade, Cascavel-PR, ZIP 85.819-110, Brazil (e-mail: dr.mendonca@uol.com.br).
\end{abstract}

\begin{abstract}
Keywords

- Direct pulp capping

- mineral trioxide aggregate

- Biodentine

- tricalcium silicate

Objectives Conduct a histological comparison of the pulp response to different materials, with a focus on the continuity and morphology of the mineralized barrier after direct pulp capping.

Materials and Methods One hundred and eight maxillary first molars of 54 Wistar rats were subject to direct pulp capping and divided into three groups according to the materials used: calcium hydroxide $(\mathrm{CH})$, mineral trioxide aggregate (MTA), and Biodentine. All cavities were sealed, and the animals were euthanized at 7,14 , and 21 days. Descriptive histological evaluation of the inflammation and formation of the mineralized barrier was performed.

Statistical Analysis Statistical analyses were performed using the Kruskal-Wallis test, which was complemented by the Dunn test; differences with $p<0.05$ were considered statistically significant.

Results The results showed that MTA and Biodentine elicited less intense inflammatory reactions than $\mathrm{CH}$. With respect to the formation and quality of the dentin barrier formed, differences were observed at 21 days between the analyzed groups; the best results being obtained following treatment with MTA and Biodentine.

Conclusion MTA and Biodentine induced formation of a more continuous and uniform mineralized barrier with less intense pulp response than $\mathrm{CH}$.
\end{abstract}

\section{Introduction}

Direct pulp capping is a treatment for exposed vital pulp; it involves the placement of a dental material over the exposed area to facilitate both the formation of a protective barrier and the maintenance of the vital pulp., ${ }^{1,2}$ From a more precise clinical perspective, direct pulp capping is a clinical technique that lies between indirect pulp capping and pulpotomy. ${ }^{2}$ The direct pulp capping procedure aims to maintain pulp vitality. This procedure utilizes calcium hydroxide $(\mathrm{CH})$ which, in contact with the pulp tissue, promotes superficial necrolysis with zones of necrosis and inflammatory response; these may be attributed to its $\mathrm{pH}$ (almost 13.0) and the formation

DOI https://doi.org/ 10.1055/s-0040-1715986 ISSN 1305-7456. of a hard tissue barrier with an amorphous pattern. ${ }^{3}$ This material presents disadvantages such as porosity in the dentin bridge produced, poor adherence to the dentin, and failure to produce good long-term sealing. ${ }^{4}$

In 1993, Torabinejad developed a calcium silicate cement, known as mineral trioxide aggregate (MTA), which was indicated for root perforations and later for pulp caps. ${ }^{5}$ The chemical reaction of this material in direct contact with the pulp leads to the formation of calcium crystals, similar to those found in $\mathrm{CH}^{2}{ }^{2}$ The superior nature of MTA in comparison with $\mathrm{CH}$ in terms of sealing capacity, dentin quality ${ }^{6}$ and biocompatibility ${ }^{7}$ supports the replacement of $\mathrm{CH}$ by this material in direct pulp capping procedures. ${ }^{8}$

(c) 2020. European Journal of Dentistry.

This is an open access article published by Thieme under the terms of the Creative Commons Attribution-NonDerivative-NonCommercial-License, permitting copying and reproduction so long as the original work is given appropriate credit. Contents may not be used for commercial purposes, or adapted, remixed, transformed or built upon. (https://creativecommons.org/licenses/by-nc-nd/4.0/)

Thieme Medical and Scientific Publishers Pvt. Ltd., A-12, 2nd Floor, Sector 2, Noida-201301 UP, India 
New tricalcium silicate-based cement Biodentine (Septodont, France) was released in 2011.9 These are composed of tricalcium silicate, dicalcium silicate, calcium carbonate, calcium oxide, and zirconium oxide (radiopacifier) as well as liquid containing water, calcium chloride (water-soluble polymer, responsible for accelerating the setting time of the material), and modified polycarboxylate (which imparts plasticity to the material). ${ }^{10}$ Initially, these cements were developed as substitutes for dentin; however, they presented favorable results in inducing the formation of mineralized tissue when in direct contact with the pulp. ${ }^{11,12}$ In addition to its biocompatibility, ${ }^{13,14}$ it also presented advantages such as viscosity and reduced setting time in comparison with MTA. ${ }^{15}$ However, a deeper understanding of the influence of the constituents of the pulp capping materials on their properties is necessary. ${ }^{16}$

Research on teeth from animal models has been widely used; according to Dammaschke, ${ }^{17}$ the Wistar rat molar, which is anatomically, biologically, and histologically similar to the human tooth, is considered a miniature molar and exhibits a superior repair speed compared with the human tooth. Owing to ease of handling and similar histological response in direct pulpal capping procedures, the Wistar rat molar represents a valid model for research. ${ }^{18}$

In view of the need to better understand the performance of various materials indicated for the protection of histologically exposed pulps, the aim of this study was to conduct a histological comparison of the pulp response to different materials, with a focus on the continuity and morphology of the mineralized barrier after direct pulp capping.

\section{Materials and Methods}

\section{Sample Size}

From the data obtained in a pilot test, the sample size was determined using the BioStat 5.3 program (Instituto Mauá, Amazonas, Brazil), considering an analysis power of 0.80 , minimum difference between the means of 0.22 , and standard deviation (SD) of the mean error 0.11 , which guaranteed a minimum of six sample units per experimental group.

\section{Animals}

A total of 54 male rats weighing approximately $200 \mathrm{~g},{ }^{19}$ of the 56-day-old Wistar variety, were purchased from the Western State University of Paraná (UNIOESTE) Central Bioterium. They were adapted and kept in the Sectoral Bioterium of the UNIOESTE, Cascavel, Paraná, Brazil, in collective cages of polyethylene $(43 \times 30 \times 15 \mathrm{~cm})$, in pairs, under controlled temperature conditions ranging between $22^{\circ} \mathrm{C}$ and $25^{\circ} \mathrm{C}$, relative humidity of $55 \%$, and photoperiod of 12 hour (light period from 7:00 am to 7:00 pm). The experimental procedures were in accordance with the Ethical Principles on Animal Experimentation adopted by the Brazilian College of Animal Experimentation (COBEA), and they were analyzed and approved by the Committee on Ethics in Animal Experimentation (CEEA) of UNIOESTE, no. 14/18-CEUA.

\section{Experimental Groups}

The animals were randomly assigned to three treatment groups (CH, MTA, and Biodentine), with 18 animals per group. Each group was subdivided into three time periods of 7,14 , and 21 days, with six animals per group per period (-Table 1).

\section{Pulp Capping}

At 56 days, the animals were anesthetized with a combination of $1 \mathrm{~mL}$ of ketamine (injectable Dopalen, Ceva Saúde Animal, Paulínia, SP, Brazil) and $0.2 \mathrm{~mL}$ of xylazine (injectable Anasedan, Ceva Saúde Animal, Paulínia, SP, Brazil) and diluted in $3.8 \mathrm{~mL}$ of saline, intraperitoneally $(0.1 \mathrm{~mL}$ of solution $/ 50 \mathrm{~g}$ of animal body weight). ${ }^{17}$ After anesthesia, the animals were placed on an appropriate surgical table, ${ }^{20}$ which allowed the opening of the oral cavity, facilitating access to the maxillary teeth ( - Fig. 1).

On the occlusal side of the maxillary first molars (right and left), circular cavities were made using an electric motor (Driller, BLM 600 Plus, Carapicuíba, SP, Brazil) at $3000 \mathrm{rpm}$ with an ISO 006 LN 28-mm drill bit (D 205 LN; Dentsply, Maillefer, Ballaigues, Switzerland), and pulp exposures verified with C+\#15 files (Dentsply, Maillefer, Ballaigues, Switzerland). ${ }^{17,21}$

Pulp hemorrhage was controlled, and the cavity was dried with sterile absorbent paper cones (-Fig. 2A). Capping was performed on pulp exposures (-Fig. 2B) for the following groups G1: CH (Calcium Hydroxide P.A., Biodynamic, Ibiporã, PR, Brazil) in powder form; G2: MTA (White MTA; Angelus, Londrina, PR, Brazil), handled according to the manufacturer's guidelines on glass plate; and G3: Biodentine (Septodont; Saint-Maur-des-Fosses, France), handled on a glass plate. The materials were applied with the aid of a metallic device, the MTA Applicator (MTA Applicator; Angelus, Londrina, PR, Brazil), and the cavities were sealed to avoid exposure to the resin-modified glass ionomer (Vitremer; 3M ESPE do Brasil Ltda., Sumaré, SP, Brazil) (-Fig. 2C) and photoactivated for 20 seconds with the Radii-cal device (SDI-Innovative

Table 1 Groups of experimental animals with details of periods of euthanasia and material used in each group

\begin{tabular}{|l|l|l|l|l|}
\hline Description of group & Animals & \multicolumn{3}{|c|}{ Euthanasia } \\
\cline { 3 - 6 } & & 7 days & 14 days & 21 days \\
\hline CH & 18 & 6 & 6 & 6 \\
\hline MTA & 18 & 6 & 6 & 6 \\
\hline Biodentine & 18 & 6 & 6 \\
\hline
\end{tabular}




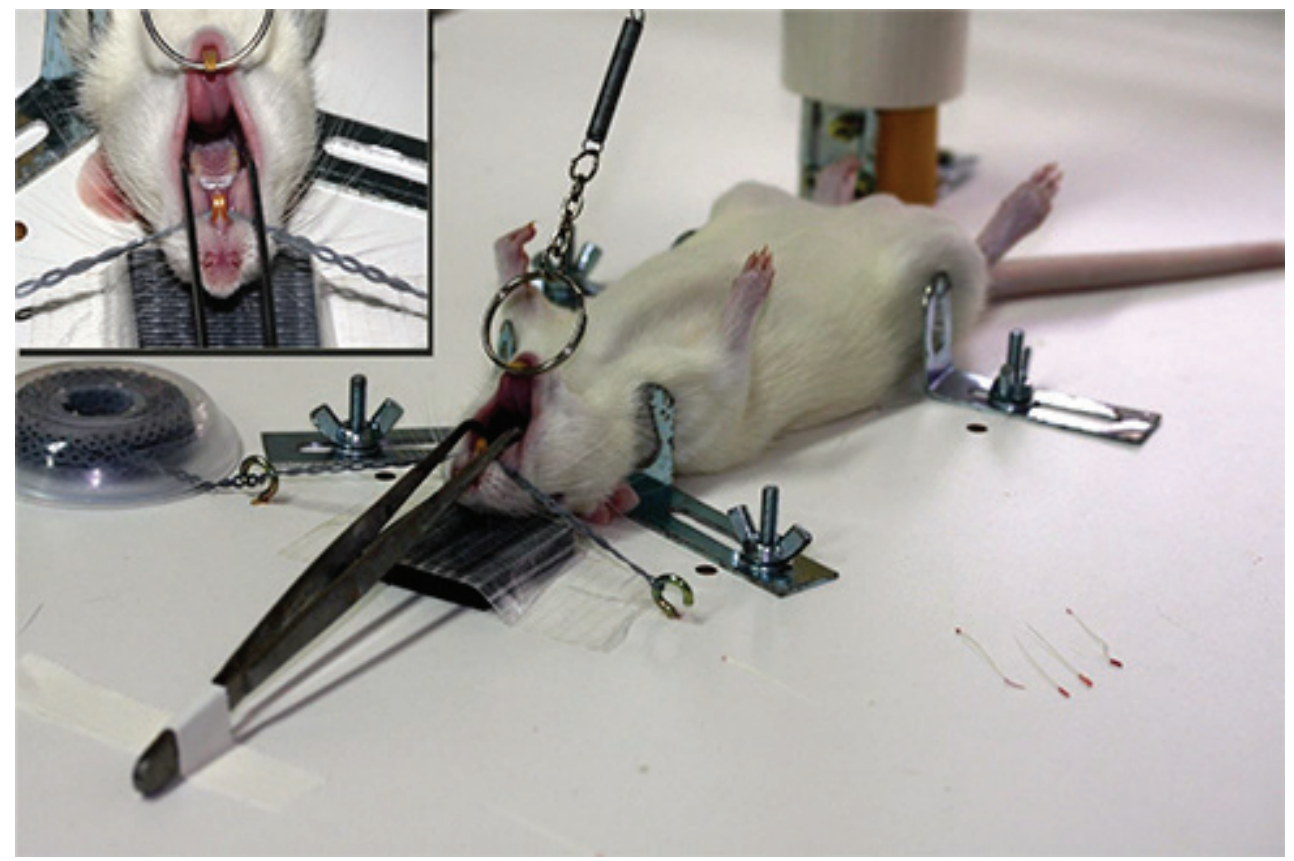

Fig. 1 Operating table for immobilization and maintenance of the oral cavity opening of the animal.

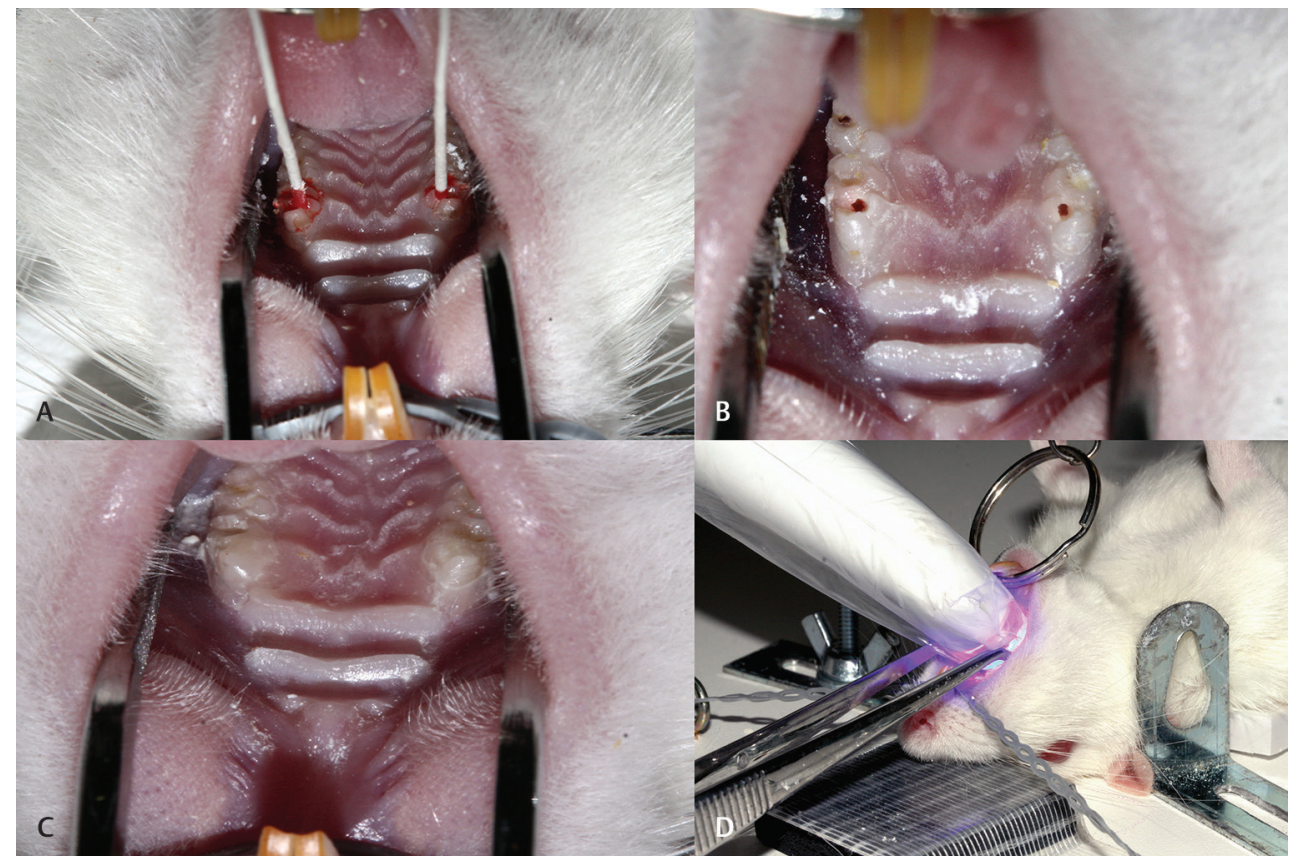

Fig. 2 (A) Hemorrhage control with paper cones; (B) rounded cavities; site of exposure; (C) sealing with Vitremer glass ionomer (3M-ESPE); (D) photopolymerization for 20 seconds.

Dental Products, Australia), with a power of $1200 \mathrm{~mW} / \mathrm{cm}^{2}$ ( - Fig. 2D). At the end of the experimental period of 7,14 , and 21 days after pulp capping, the animals were euthanized by guillotine decapitation.

\section{Histological Processing}

The jaws were removed, dissected, identified, and fixed in $10 \%$ formalin solution for 48 hours, washed in running water, and stored in $70 \%$ alcohol. After this period, the samples were washed in running water for 1 hour and immersed in a decalcifying acid solution (hydrogen chloride; UN 1789, Allkimia, Campinas, SP, Brazil) for 24 hours at room temperature and evaluated to verify the degree of decalcification achieved.

After decalcification, the samples were again washed in tap water for 1 hour for automatic histological processing, which lasted approximately 12 hours (Automatic Tissue Processor; Leica Microsystems ${ }^{\circledR}$ TP1020, Nussloch, Germany), with paraffin blocks (Purified Paraffin; Vetec Química Fina, Rio de Janeiro, RJ, Brazil). Cuts of $5-\mu \mathrm{m}$ thickness were obtained using 
a semiautomatic microtome (Hestion; ERM3000, Daintree Scientific, St. Helens, Australia), and histological sections were stained with Harris hematoxylin and eosin (HE).

\section{Histological Analysis}

The histological analyses were performed by a blinded calibrated observer, in which the on-site aspects of the pulp exposure were evaluated using an optical microscope with 40x- and 100x-objective lenses (Leica Microsystems ICC50 HD; Nussloch, Germany) and an image capture system (Las Ez-Leica, version 2.10, 2012). The following parameters were analyzed: inflammatory response, continuity and morphology of the dentine barrier formed. The results were classified according to the scores described in - Table $\mathbf{2}$. The results were evaluated by scores using the image capture system. ${ }^{22}$

\section{Statistical Analysis}

Statistical analyses were performed using the BioStat 5.3 program (Instituto Mauá; Amazonas, Brazil), using the KruskalWallis test and complemented by the Dunn test; differences with $p<0.05$ were considered statistically significant.

\section{Results}

Pulp response presented severe hyperemia at 7 days ( - Fig. 3) in all experimental groups, irrespective of the material used. The analysis of the acute inflammatory infiltrate demonstrated varying extensions: the group treated with $\mathrm{CH}$ exhibited the greatest extension of the inflammatory processes, followed by the MTA and Biodentine groups, respectively. Necrotic remains and dentinal scrapings were present in all animals of the various groups.

At 14 days, $70 \%$ of the samples capped with $\mathrm{CH}$ showed necrosis and microabscess areas in the root canals, with single-cell chronic inflammatory infiltrate in the periapical region. The other samples exhibited initiation of amorphous formation of mineralized material in the middle of cellular tissue. Further, the pulps, capped with MTA and Biodentine, presented amorphous formation of mineralized tissue at the site of exposure and in contact with the material used, both in evolution and continuity with dentin (-Fig. 4). Analysis of the mineralized barrier revealed statistical differences in continuity, with those capped with $\mathrm{CH}$ differing from those of the MTA group (-Table 3). Differences in terms of morphology were also observed: the morphology of those capped with $\mathrm{CH}$ was different from those capped with either the MTA and Biodentine. However, between $\mathrm{CH}$ and MTA, no statistically significant differences were found (-Table 4).

At 21 days, higher amounts with discrete inflammatory infiltrate of pulp and formation of hard tissue were present in all cases; however, in the MTA and Biodentine groups, the barrier formed obliterated, on occasion, the entire root canal, with a formation aspect similar to that of pulpal calculus (atubular dentin) ( - Fig. 5). No statistically significant differences were found in the morphology of the mineralized barrier (-Table 3), However, between $\mathrm{CH}$ and Biodentine, statistically significant differences were found for continuity of the mineralized barrier ( - Table 4 ).

\section{Discussion}

In this study, an experimental animal model (Wistar rat) was used, owing to the ease of experimental handling, coupled

Table 2 Scores used for histological analysis

\begin{tabular}{|l|l|}
\hline \multicolumn{2}{|c|}{ Mineralized barrier } \\
\hline Scores & Continuity \\
\hline 1 & Complete \\
2 & Partially present \\
3 & Absent \\
\hline Scores & Morphology \\
\hline 1 & Tubular dentin \\
2 & Irregular deposition of hard tissue or dentin \\
3 & Only small layer of hard tissue deposition \\
4 & Absence of hard tissue deposition \\
\hline
\end{tabular}

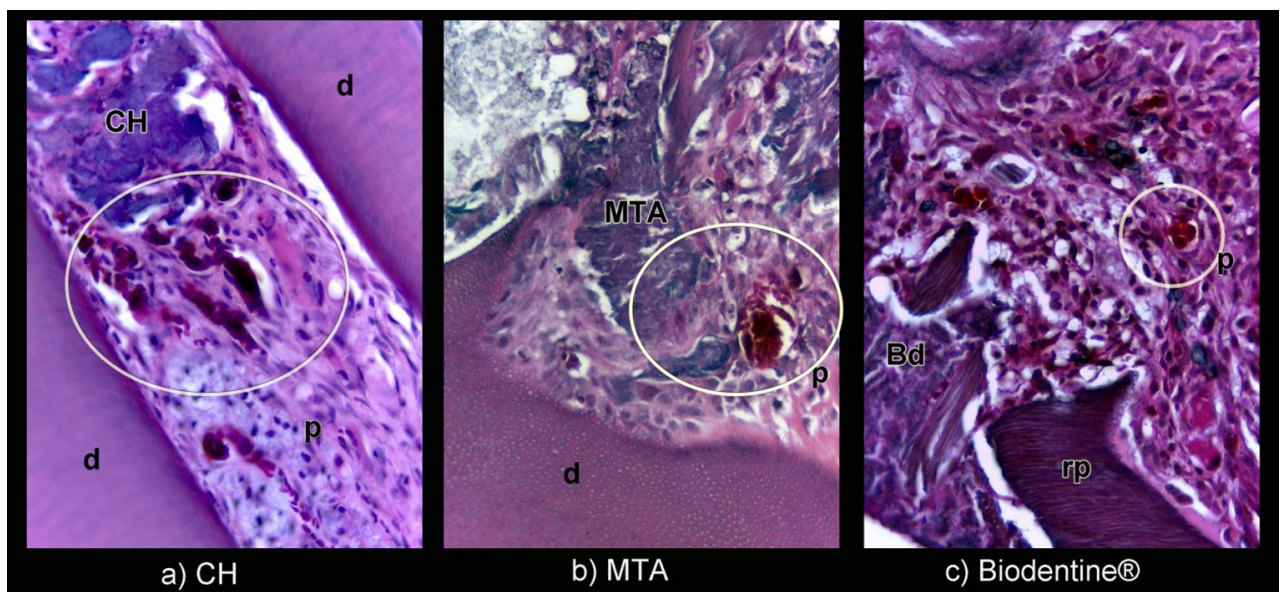

Fig. 3 Photomicrograph of the pulps of the euthanized animals at 7 days after pulp exposure in the various experimental groups, according to the material used: (a) $\mathrm{CH}$; (b) MTA; and (c) Biodentine. Severe pulp hyperemia in all samples (circle) with higher intensity for $\mathrm{CH}$, followed by MTA and Biodentine; $\mathrm{p}=$ pulp; $d$ = dentin; $r d$ = dentin scrapings; $\mathrm{CH}=$ calcium hydroxide; $\mathrm{MTA}=\mathrm{MTA} ; \mathrm{Bd}=$ Biodentine. Hematoxylin and eosin staining. Magnification: 40x. 


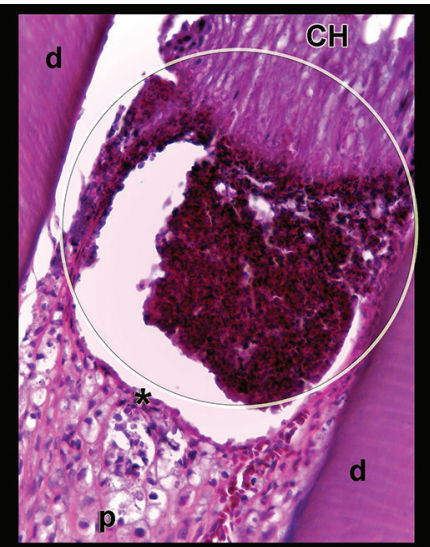

a) $\mathrm{CH}$

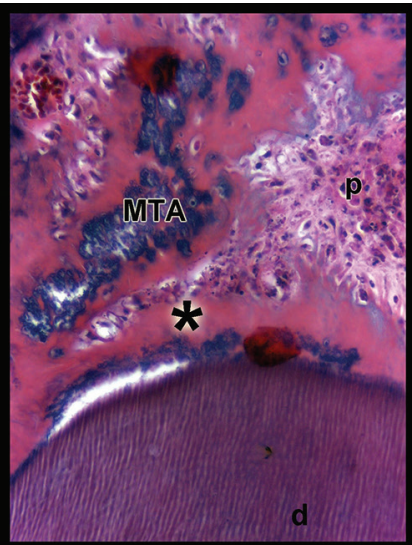

b) MTA

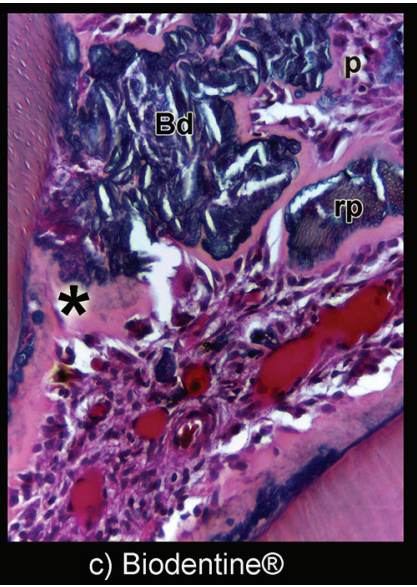

c) Biodentine®

Fig. 4 Photomicrograph of the pulps of the euthanized animals at 14 days after pulp exposure in the various experimental groups, according to the material used (a) $\mathrm{CH}$; (b) MTA; and (c) Bd. Analysis of the dentin barrier formed (a) $\mathrm{CH}$ = calcium hydroxide-the circled region highlights the transition zone of necrosis (top of the circle) and microabscess (bottom of the circle) induced by $\mathrm{CH}$ and the beginning of amorphous formation of mineralized tissue $\left({ }^{*}\right)$; (b) MTA = amorphous formation of mineralized tissue $\left(^{*}\right)$ and pulpar microabscess area (p); (c) Bd = Biodentine-amorphous formation of mineralized tissue $\left({ }^{*}\right) ; p=$ pulp; $d$ = dentin; * = dentin bridge; $r d=$ dentinal scrapings. Staining of hematoxylin and eosin. Magnification: 40x.

Table 3 Histological analysis of the tooth pulp for mineralized barrier-continuity in experimental animals according to time

\begin{tabular}{|l|l|l|l|}
\hline Continuity & 7 days & 14 days & 21 days \\
\hline $\mathrm{CH}$ & $3.00( \pm 0.00) \mathrm{Aa}$ & $2.90( \pm 0.32) \mathrm{Aa}$ & $2.67( \pm 0.50) \mathrm{Aa}$ \\
\hline MTA & $3.00( \pm 0.00) \mathrm{Aa}$ & $2.00( \pm 0.00) \mathrm{Ba}$ & $1.91( \pm 0.94) \mathrm{Aba}$ \\
\hline Biodentine & $3.00( \pm 0.00) \mathrm{Aa}$ & $2.10(0.48) \mathrm{ABa}$ & $1.70( \pm 0.48) \mathrm{Bb}$ \\
\hline
\end{tabular}

Abbreviations: $\mathrm{CH}$, calcium hydroxide; MTA, mineral trioxide aggregate.

Values expressed as mean \pm standard deviation; Kruskal-Wallis test, complemented by the Dunn test. Lower-case letters (line) and different capital letters (column) mean statistically significant differences $=p<0.05$.

Table 4 Histological analysis of the tooth pulp for mineralized barrier-morphology in experimental animals according to time

\begin{tabular}{|l|l|l|l|}
\hline Morphology & 7 days & 14 days & 21 days \\
\hline CH & $4.00( \pm 0.00) \mathrm{Aa}$ & $3.70( \pm 0.48) \mathrm{Aa}$ & $3.22( \pm 0.97) \mathrm{Aa}$ \\
\hline MTA & $3.63( \pm 0.52) \mathrm{Aa}$ & $2.50( \pm 0.55) \mathrm{Ba}$ & $2.82( \pm 0.98) \mathrm{Aa}$ \\
\hline Biodentine & $3.90( \pm 0.32) \mathrm{Aa}$ & $2.70( \pm 0.67) \mathrm{Ba}$ & $2.20( \pm 0.42) \mathrm{Ab}$ \\
\hline
\end{tabular}

Abbreviations: $\mathrm{CH}$, calcium hydroxide; MTA, mineral trioxide aggregate.

Values expressed as mean \pm standard deviation; Kruskal-Wallis test, complemented by the Dunn test. Lower-case letters (line) and different capital letters (column) mean statistically significant differences $=p<0.05$.

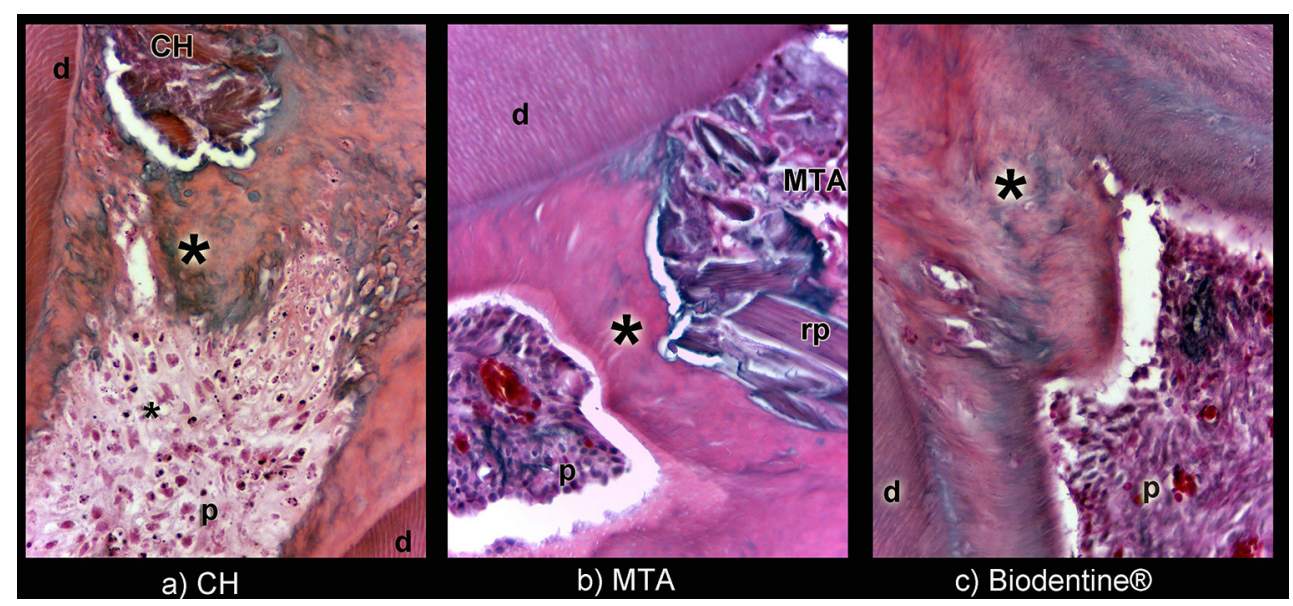

Fig. 5 Photomicrograph of the pulps of the euthanized animals at 21 days after pulp exposure in the various experimental groups. Analysis of the formed dentin barrier. (a) $\mathrm{CH}=$ calcium hydroxide-formation of the dentin barrier $\left({ }^{*}\right)$; (b) MTA $=$ formation of the dentin barrier $\left({ }^{*}\right)$; $(\mathbf{c})$ $\mathrm{Bd}=$ Biodentine-formation of the dentin barrier $\left({ }^{*}\right) ; \mathrm{p}=$ pulp; $\mathrm{d}=$ dentin; ${ }^{*}=$ dentin bridge; $r d=$ dentinal scrapings. Staining of hematoxylin and eosin. Magnification: 40x. 
with the fact that the pulp response and recovery after direct pulp capping of rodent teeth are histologically comparable with that in humans. ${ }^{17,19,21}$

Dentin barrier formation occurs in response to various injuries, and this can be characterized as reactional dentin (primary odontoblasts) or reparative dentin, composed of neo-odontoblasts originating from dental pulp stem cells (DPSCs), cells with multiple differentiation potentials and capacity for tertiary dentinogenesis. ${ }^{23-25}$ For the mineralized barrier formation, the DPSCs migrate, proliferate, and differentiate into neo-odontoblasts, which then synthesize a matrix to form the tertiary dentin at the injury sites. ${ }^{26}$

There are several types of stem cells of dental origin (DSCs), for example, DPSCs, ${ }^{23}$ stem cells from human exfoliated deciduous tooth, ${ }^{27}$ periodontal ligament stem cells, ${ }^{28}$ alveolar bone derived mesenchymal stem cells, ${ }^{29}$ dental follicle progenitor cells,,$^{30}$ stem cells from the apical part of the dental papilla, ${ }^{31}$ teeth germ progenitor cells (Ikeda et al, 2008), and gingival mesenchymal stem cells. ${ }^{31,32}$ DPSCs are the first type of DSCs to be isolated; they exhibit pluripotency and a typical fibroblast-like morphology. ${ }^{23}$

DPSCs were isolated and their differentiation potential was demonstrated in various media, such as dentinogenic, neurogenic, osteogenic, chondrogenic, adipogenic, and myogenic media. ${ }^{33}$ In dentistry, DSCs can be used in the repair of damaged dentin, pulp regeneration and revascularization, osseointegration, and periodontal disorders. ${ }^{34,35}$

In this study, we used the three materials as direct pulping protect materials: $\mathrm{CH}, \mathrm{MTA}$, and Biodentine. $\mathrm{CH}$ cement was one of the first materials used in the treatment of live pulps. ${ }^{36}$ $\mathrm{CH}$ releases a large amount of relatively short time. The factors influencing the alkaline environment required for pulp healing, to promote immediate selection, the stimulation of hydroxyapatite, and the formation of tertiary dentin in the affected tissues were determined. In addition, the hydroxyls of this material neutralize the effects of osteoclasts, bond with hydrogen and form the $\mathrm{H}_{2} \mathrm{O}$ molecule, and maintain the optimum $\mathrm{pH}$ for auxiliary pyrophosphate and remineralization activity. ${ }^{37}$ However, $\mathrm{CH}$ may possibly wound the primary tooth pulp to permit internal resorption or dystrophic calcification.

MTA and Biodentine have a very similar chemical reaction: first, the solid-liquid interface is formed on the surface of the particles with immediate dissolution of ions, such as $\mathrm{Ca}+$ that migrate to the solution forming $\mathrm{CaOH}_{2}$; second, $\mathrm{CaOH}_{2}$ is attracted by the hydroxyl groups, resulting in the formation of calcium silicate hydrate. This gelatinous layer has a negative character and can act as a nucleation site to form hydroxyapatite. In the third phase, the hydrated calcium silicate provides significant and continuous amounts of $\mathrm{CH}$ during the first hours of the setting reaction, leading to an increase in $\mathrm{pH}$ and the concentration of calcium ions in the adjacent areas. Compared with $\mathrm{CH}$ and MTA, Biodentine has more ions. It consists of tricalcium silicate, dicalcium silicate as a second core material, calcium carbonate, oxide as filler, iron oxide shade, and zirconium oxide as a radio-opacifier. The liquid, on the contrary, contains calcium chloride as a setting accelerator and a water-reducing agent. ${ }^{38,39}$
In our study, histological analysis of samples from the 7-day period demonstrated the capacity of the pulp to respond to damage, which manifested during this period as inflammation of the pulp tissue. According to Goldberg, ${ }^{40}$ cell repair begins after inflammation control, with replacement of the injured or necrotic region by undifferentiated cells. After transformation, these cells give rise to tissue similar to the previous undamaged tissue, with three successive phases of cell renewal: slight inflammation associated with cell recruitment, cell proliferation filling the lesion site, and cell differentiation in the pulp, creating neo-odontoblasts for the production of reparative dentin. These findings were similar to our results.

Our results indicate an outcome characterized by initial pulp inflammation and a zone of necrosis, similar to that described in other studies, thereby corroborating previous research. ${ }^{41-43}$ Analysis of dentin bridge formation at 7 days did not reveal statistically significant differences between the three materials tested, similar to Dammaschke et $\mathrm{al}^{18}$ with similar immunohistochemical analysis results for $\mathrm{CH}$ and MTA in the first week after direct pulp capping.

Although the use of $\mathrm{CH}$ in the pure form was recommended in a previous study, ${ }^{25}$ this material promoted a more intense inflammatory reaction ${ }^{41,44}$ compared with MTA and Biodentine, which demonstrated similar results. Previous studies have shown that $\mathrm{CH}$ elicits the generation of zones of necrosis when in contact with pulp tissues, which may be attributed to its initial caustic effect. ${ }^{45}$

Therefore, the intense inflammatory response elicited by $\mathrm{CH}$, in comparison with that generated by MTA and Biodentine, may influence the formation of a mineralized barrier. This finding coincides with the difference revealed at 14 days by the analysis of the continuity of the mineralized barrier formation, where the $\mathrm{CH}$ presented an inferior result compared with MTA. All samples capped with MTA showed partial dentin bridge formation. In addition, morphological analysis at 14 days showed that $\mathrm{CH}$ presented statistically lower values than MTA and Biodentine, whose results were similar to each other.

The barriers formed using $\mathrm{CH}$ were porous, and therefore not ideal for a proper bacterial sealing, as described by Paranjpe et al. ${ }^{46} \mathrm{The} \mathrm{CH}$ presented a porous barrier as from the second week, as also reported by Tran et al, ${ }^{43}$ who concluded that $\mathrm{CH}$ used in direct pulp capping produces porous barriers at 14 days in rat pulps compared with Biodentine. In contrast, denser and more extensive formations were observed when MTA or Biodentine were used, in which the mineralization formed appeared as an atubular dentin, similar to pulp calcification and different from the reactional dentin. ${ }^{47}$

In our study, morphological analysis of the mineralized barrier formed indicated superior irregular deposition of hard tissue for MTA and Biodentine when compared with $\mathrm{CH}$, which presented small depositions of hard tissue at 14 days. According to Laurent et $\mathrm{al}^{10}{ }^{10}$ Biodentine exhibits a 12-minute setting time and increased sealing capacity. All materials promote alkalinization of the medium, owing to the $\mathrm{pH}$ of around 12.5 , which confers antibacterial power 
to the materials. In routine clinical settings, the Biodentine material deserves special attention because it induces the formation of a mineralized barrier, similar to that induced by MTA, and a reduced setting time, thereby allowing definitive restorations to be made after direct pulp capping. This circumvents the need for additional clinical sessions, thereby eliminating the risk of new pulp exposure and secondary contamination, significantly reducing patient stress and cost of treatment.

At 21 days, morphological analysis of the mineralized barrier formed in the various groups revealed superior results for Biodentine relative to $\mathrm{CH}$. It is known that the availability of calcium ions stimulates the formation of the calcium carbonate precipitate, which contributes to mineralization. It seems clear that the form and time for the release of calcium and hydroxyl ions interfere with the formed mineralized barrier. In $\mathrm{CH}$, the release of the calcium ions occurs rapidly, which acts as an irritant to the tissues and generates a caustic surface effect. ${ }^{29}$ Calcium silicate materials exhibit a slower and more gradual release, and disperse larger amounts of calcium ions compared with $\mathrm{CH}$-based cements. Biodentine, however, exhibits greater calcium release and extended alkaline activity, as well as better mechanical properties than MTA. ${ }^{11,48}$

Our results demonstrate the superiority of the new materials, MTA and Biodentine over $\mathrm{CH}$, when used for direct capping of live pulps. The use of new materials based on calcium silicate presents a viable alternative, with favorable histological characteristics relative to $\mathrm{CH}$, which was previously considered the gold standard for this treatment.

\section{Conflict of Interest}

None declared.

\section{Acknowledgment}

We thank Coordenadoria de Aperfeiçoamento de Pessoal de Nível Superior (CAPES; Brasília, Brazil) for providing financial support.

\section{References}

1 Bergenholtz G. Advances since the paper by Zander and Glass (1949) on the pursuit of healing methods for pulpal exposures: historical perspectives. Oral Surg Oral Med Oral Pathol Oral Radiol Endod 2005;100(2, Suppl):S102-S108

2 Komabayashi T, Zhu Q, Eberhart R, Imai Y. Current status of direct pulp-capping materials for permanent teeth. Dent Mater J 2016;35(1):1-12

3 Reston EG, de Souza Costa CA. Scanning electron microscopy evaluation of the hard tissue barrier after pulp capping with calcium hydroxide, mineral trioxide aggregate (MTA) or ProRoot MTA. Aust Endod J 2009;35(2):78-84

4 Cohenca N, Paranjpe A, Berg J. Vital pulp therapy. Dent Clin North Am 2013;57(1):59-73

5 Ford TR, Torabinejad M, Abedi HR, Bakland LK, Kariyawasam SP. Using mineral trioxide aggregate as a pulp-capping material. J Am Dent Assoc 1996;127(10):1491-1494

6 Min K-S, Park H-J, Lee S-K, et al. Effect of mineral trioxide aggregate on dentin bridge formation and expression of dentin sialoprotein and heme oxygenase- 1 in human dental pulp. J Endod 2008;34(6):666-670
7 Zhao W, Wang J, Zhai W, Wang Z, Chang J. The self-setting properties and in vitro bioactivity of tricalcium silicate. Biomaterials 2005;26(31):6113-6121

8 Paranjpe A, Smoot T, Zhang H, Johnson JD. Direct contact with mineral trioxide aggregate activates and differentiates human dental pulp cells. J Endod 2011;37(12):1691-1695

9 Kunert M, Lukomska-Szymanska M. Bio-Inductive Materials in Direct and Indirect Pulp Capping-A Review Article. Materials (Basel) 2020;13(5):1204

10 Laurent P, Camps J, About I. Biodentine(TM) induces TGF-1 release from human pulp cells and early dental pulp mineralization. Int Endod J 2012;45(5):439-448

11 Gandolfi MG, Siboni F, Polimeni A, et al. In vitro screening of the apatite-formation ability, biointeractivity and physical proprieties of a tricalcium silicate material for Endodontics and restorative dentistry. Dent J 2013;1:41-60

12 Tziafa C, Koliniotou-Koumpia E, Papadimitriou S, Tziafas D. Dentinogenic responses after direct pulp capping of miniature swine teeth with Biodentine. J Endod 2014;40(12):1967-1971

13 Mori GG, Teixeira LM, de Oliveira DL, Jacomini LM, da Silva SR. Biocompatibility evaluation of biodentine in subcutaneous tissue of rats. J Endod 2014;40(9):1485-1488

14 Bossù $M$, Iaculli F, Di Giorgio G, Salucci A, Polimeni A, Di Carlo S. Different pulp dressing materials for the pulpotomy of primary teeth: A systematic review of the literature. J Clin Med 2020;9(3):E838

15 Pérard M, Le Clerc J, Watrin T, et al. Spheroid model study comparing the biocompatibility of Biodentine and MTA. J Mater Sci Mater Med 2013;24(6):1527-1534

16 Saghiri MA, Orangi J, Asatourian A, et al. Calcium silicate-based cements and functional impacts of various constituents. Dent Mater J 2017;36(1):8-18

17 Dammaschke T. Rat molar teeth as a study model for direct pulp capping research in dentistry. Lab Anim 2010;44(1):1-6

18 Dammaschke T, Stratmann U, Wolff P, Sagheri D, Schäfer E. Direct pulp capping with mineral trioxide aggregate: an immunohistologic comparison with calcium hydroxide in rodents. J Endod 2010;36(5):814-819

19 Bowen WH. Rodent model in caries research. Odontology 2013;101(1):9-14

20 Kirschneck C, Proff P, Fanghaenel J, Behr M, Wahlmann U, Roemer P. Differentiated analysis of orthodontic tooth movement in rats with an improved rat model and three-dimensional imaging. Ann Anat 2013;195(6):539-553

21 Simon S, Cooper P, Smith A, Picard B, Ifi CN, Berdal A. Evaluation of a new laboratory model for pulp healing: Preliminary study. Int Endod J 2008;41(9):781-790

22 Nowicka A, Lipski M, Parafiniuk M, et al. Response of human dental pulp capped with biodentine and mineral trioxide aggregate. J Endod 2013;39(6):743-747

23 Gronthos S, Mankani M, Brahim J, Robey PG, Shi S. Postnatal human dental pulp stem cells (DPSCs) in vitro and in vivo. Proc Natl Acad Sci U S A 2000;97(25):13625-13630

24 Wang X, He H, Wu X, Hu J, Tan Y. Promotion of dentin regeneration via CCN3 modulation on Notch and BMP signaling pathways. Biomaterials 2014;35(9):2720-2729

25 Murray PE, Hafez AA, Smith AJ, Windsor LJ, Cox CF. Histomorphometric analysis of odontoblast-like cell numbers and dentine bridge secretory activity following pulp exposure. Int Endod J 2003;36(2):106-116

26 Goldberg M, Lacerda-Pinheiro S, Jegat N, et al. The impact of bioactive molecules to stimulate tooth repair and regeneration as part of restorative dentistry. Dent Clin North Am 2006;50(2):277-298, $x$

27 Miura M, Gronthos S, Zhao M, et al. SHED: stem cells from human exfoliated deciduous teeth. Proc Natl Acad Sci U S A 2003;100(10):5807-5812 
28 Seo BM, Miura M, Gronthos S, et al. Investigation of multipotent postnatal stem cells from human periodontal ligament. Lancet 2004;364(9429):149-155

29 Matsubara T, Suardita K, Ishii M, et al. Alveolar bone marrow as a cell source for regenerative medicine: differences between alveolar and iliac bone marrow stromal cells. J Bone Miner Res 2005;20(3):399-409

30 Morsczeck C, Götz W, Schierholz J, et al. Isolation of precursor cells (PCs) from human dental follicle of wisdom teeth. Matrix Biol 2005;24(2):155-165

31 Zhang Q, Shi S, Liu Y, et al. Mesenchymal stem cells derived from human gingiva are capable of immunomodulatory functions and ameliorate inflammation-related tissue destruction in experimental colitis. J Immunol 2009;183(12):7787-7798

32 Sonoyama W, Liu Y, Fang D, et al. Mesenchymal stem cell-mediated functional tooth regeneration in swine. PLoS One 2006;1:e79

33 Hilkens P, Gervois P, Fanton Y, et al. Effect of isolation methodology on stem cell properties and multilineage differentiation potential of human dental pulp stem cells. Cell Tissue Res 2013;353(1):65-78

34 Sharpe PT. Dental mesenchymal stem cells. Development 2016;143(13):2273-2280

35 Chalisserry EP, Nam SY, Park SH, Anil S. Therapeutic potential of dental stem cells. J Tissue Eng 2017;8:2041731417702531

36 Smaïl-Faugeron V, Glenny AM, Courson F, Durieux P, Muller-Bolla M, Fron Chabouis H. Pulp treatment for extensive decay in primary teeth. Cochrane Database Syst Rev 2018;5:CD003220

37 Niinuma A. Newly developed resinous direct pulp capping agent containing calcium hydroxide (MTYA1-Ca) Int Endod J 1999;32(6):475-483

38 Gandolfi MG, Ciapetti G, Taddei P, et al. Apatite formation on bioactive calcium-silicate cements for dentistry affects surface topography and human marrow stromal cells proliferation. Dent Mater 2010;26(10):974-992
39 Zanini M, Sautier JM, Berdal A, Simon S. Biodentine induces immortalized murine pulp cell differentiation into odontoblast-like cells and stimulates biomineralization. J Endod 2012;38(9):1220-1226

40 Goldberg M, Farges JC, Lacerda-Pinheiro S, et al. Inflammatory and immunological aspects of dental pulp repair. Pharmacol Res 2008;58(2):137-147

41 Nair PNR, Duncan HF, Pitt Ford TR, Luder HU. Histological, ultrastructural on the response of healthy human pulps to experimental capping with mineral trioxide aggregate: a randomized controlled trial. Int Endod J 2008;41:422-444

42 Accorinte MLR, Loguercio AD, Reis A, et al. Response of human dental pulp capped with MTA and calcium hydroxide powder. Oper Dent 2008;33(5):488-495

43 Tran XV, Gorin C, Willig C, et al. Effect of a calcium-silicate-based restorative cement on pulp repair. J Dent Res 2012;91(12):1166-1171

44 Mente J, Geletneky B, Ohle M, et al. Mineral trioxide aggregate or calcium hydroxide direct pulp capping: an analysis of the clinical treatment outcome. J Endod 2010;36(5):806-813

45 Schröder U. Effects of calcium hydroxide-containing pulp-capping agents on pulp cell migration, proliferation, and differentiation. J Dent Res 1985;64(Spec No) :541-548

46 Paranjpe A, Zhang H, Johnson JD. Effects of mineral trioxide aggregate on human dental pulp cells after pulp-capping procedures. J Endod 2010;36(6):1042-1047

47 Al-Hezaimi K, Salameh Z, Al-Fouzan K. Al Rejaie M, Tay FR. Histomorphometric and micro-computed tomography analysis of pulpal response to three different pulp capping materials. J Endod 2011;37(4):507-512

48 Natale LC, Rodrigues MC, Xavier TA, Simões A, de Souza DN, Braga RR. Ion release and mechanical properties of calcium silicate and calcium hydroxide materials used for pulp capping. Int Endod J 2015;48(1):89-94 